\title{
PRELIMINARY STUDY ON THE ROCK WEATHERING EFFECT OF BACILLUS MUCILAGINOSUS
}

\author{
WU, Q. ${ }^{1}-\mathrm{HU}, \mathrm{H}^{2}{ }^{2,{ }^{*}}-\mathrm{HE}, \mathrm{L}^{1}$ \\ ${ }^{I}$ School of Biological and Food Engineering, Anyang Institute of Technology, Anyang, Henan \\ 455000, China \\ ${ }^{2}$ Collaborative Innovation Center of Sustainable Forestry in Southern China of Jiangsu \\ Province, Nanjing Forestry University, 159 Longpan Road, Nanjing, Jiangsu 210037, China \\ ${ }^{3}$ Key Laboratory of Soil and Water Conservation and Ecological Restoration in Jiangsu \\ Province, Nanjing Forestry University, 159 Longpan Road, Nanjing, Jiangsu 210037, China \\ *Corresponding author \\ e-mail:531208831@qq.com
}

(Received $9^{\text {th }}$ Jun 2019; accepted $28^{\text {th }}$ Aug 2019)

\begin{abstract}
In order to explore the mechanism of the microbial weathering of rock, study the covering green process on rocks and improve the ecological environment, the soil forming effect of weathering granite, gneiss and sandstone was studied. Using ICP-OES and SEM method, the species and capacity of metabolites produced by Bacillus mucilaginosus in the fermentation process, concentrations of various elements released from the granite, gneiss, and sandstone and rock surface morphology were assessed. Results showed that metabolites such as organic acids, amino acids and polysaccharides formed by the $B$. mucilaginosus had significant differences among three types of rocks, concerning their quantities, granite > gneiss > sandstone; metabolites mentioned above could destroy the structure of the rock, which released many oxides. According to the amount of oxides leached from the three kinds of rock fermentation liquid, more oxides such as $\mathrm{SiO}_{2}, \mathrm{Na}_{2} \mathrm{O}, \mathrm{P}_{2} \mathrm{O}_{5}, \mathrm{Fe}_{2} \mathrm{O}_{3}, \mathrm{Al}_{2} \mathrm{O}_{3}, \mathrm{CaO}, \mathrm{K}_{2} \mathrm{O}, \mathrm{MgO}, \mathrm{TiO}_{2}$ were dissolved from the fermentation liquid of the granite. $\mathrm{MnO}$ was dissolved in the highest quantities in the fermentation broth of gneiss, more than that of granite and sandstone. The result indicated that the $B$. mucilaginosus had an obvious weathering effect on three kinds of rocks, especially on the weathering ability of granite.
\end{abstract}

Keywords: Bacillus mucilaginosus, weathering, granite, gneiss, sandstone

\section{Introduction}

Silicate minerals are widely distributed in nature, about one-third of all the known minerals ( $\mathrm{Du}, 1984)$. Because of the excessive exploitation of ore in the last century, bare rock was everywhere, which had led to land degradation and a sharp decline in biodiversity (Fang et al., 2016), and ecological environment needs to be repair. However, under the natural condition, relying on the physical and chemical weathering, changing bare rock to soil usually takes 20000 years to form $1 \mathrm{~m}$ thick soil (Yang, 2013). Therefore, in order to promote the restoration of degraded ecological environment, it is urgent to have good bacterial species resources of ecological restoration and effective vegetation restoration methods. The evolution of hard rock into a bioactive and porous soil requires an extremely complex process of weathering and soil formation. All kinds of organisms living in soil fundamentally change the physical, chemical and biochemical properties of soil parent material, and promote the formation and evolution of soil ( $\mathrm{Li}, 2006)$. Hall believes that in the environment with biological existence, biological weathering rocks can play a leading role under certain conditions (Hall et al., 2005). Microorganisms are widely attached to the rock surface, which can 
affect the weathering of rocks and minerals and promote the formation of soil through growth and reproduction and the formation of biofilms (Ehrlich, 1999). Researches showed that the main microorganisms weathering the rock minerals were $B$. mucilaginosus (Zeng, 2016), Burkolderia solanacearum (Barker, 1998), Pseudomonas protegens (Wu et al., 2017a; Wu, 2016), Bacillus megatherium (Wu et al., 2017b), Aspergillus niger (Wu, 2018, 2019), Rhizobium tropici (Wang et al., 2015), Penicillium oxalicum (Song et al., 2015) and so on. The weathering effects of these microorganisms on mineral rocks include direct dissolution and mechanical damage, and indirect chemical corrosion. By reducing $\mathrm{pH}$ value and producing organic acids or inorganic acids, these microorganisms dissolve rock components and accelerate the release of $\mathrm{Si}$, Al, Ca, Mg, K and other elements from rocks (Welchm, 1993; Vandevivere et al., 1994; Sun et al., 2018; Zhang et al., 2018; Zhou et al., 2015; Li et al., 2017), which are directly supplied to plant growth and utilization (Ge and Li, 2017; Li et al., 2016).

B. mucilaginosus is an important functional bacterium widely used in microbial fertilizers. It decomposes rock minerals through mechanical damage, mineral complex, acidolysis, enzymatic hydrolysis, reduction and complexation (Zeng, 2018; Man, 2015). Štyriaková et al. studied the infection of B. mucilaginosus on basalt, granite and gneiss at different temperatures and leaching tests on potassium, calcium, magnesium, silicon, iron and aluminum, and found that the influence of temperature on microbial weathering of rocks and the change of element extraction was obvious (Štyriaková, 2012). Xiao Guoguang et al. studied the release of metabolites (organic acids, amino acids and polysaccharides) of $B$. mucilaginosus under laboratory conditions, and believed that all metabolites had a certain weathering effect on plagioclase (Xiao, 2013). To date, however, no one has discussed the effect of B. mucilaginosus on weathered soils of granite, gneiss, and sandstone.

In this experiment, the metabolites released by weathering of granite, gneiss and sandstone, and the ability of dissolution of $\mathrm{Si}, \mathrm{K}$ and other elements were compared and studied by using the $B$. mucilaginosus under laboratory conditions, which aimed at a deeper understanding of the effects and mechanism of the $B$. mucilaginosus weathering mineral rocks, cleared the role of the microbial weathering of rock, and screened good strains of weathering rock minerals, thus to provide important clues for clarifying the soil generating process, the ecological restoration, the development of sustainable agriculture and a series of scientific problems.

\section{Materials and method}

\section{Materials}

\section{Bacteria}

A B. mucilaginosus was isolated, purified and screened from the soil in Key Laboratory of Soil and Water Conservation and Ecological Restoration in Jiangsu Province, Nanjing Forestry University, China. It was identified as a B. mucilaginosus by biochemical analysis and 16s rDNA. The strain formed a raised colorless transparent colony on the nitrogen-free silicate medium, and the colony was smooth in surface, neat in its edge, with viscous and elastic, and could be drawn into silk. Its form was rod, gram reaction was negative, the optimum growth temperature was $28 \mathrm{C}$, and it was cultured for $3 \mathrm{~d}$ on the $\mathrm{N}$-containing medium. 


\section{Rock sample}

The tested granite samplings were taken from the closed mine in Jinding mountain, Wuzhong district, Suzhou; the sandstone samplings from the Yuyang mountain in Suzhou, and the gneiss samplings from the Lingzhou mine in Lianyungang. According to the XRD analysis of the collected rock samples, the mineral composition of the granite: quartz $30-35 \%$, plagioclase $20-25 \%$ and potassium feldspar $25-30 \%$, mica $10-$ $15 \%$, chlorite or vermiculite $<5 \%$, the collected rock was porphyritic granite; Main mineral composition of gneiss: quartz 30-35\%, Plagioclase 45-50\%, Mica 15-20\%; Main mineral composition of sandstone: quartz > 95\%; A small amount of feldspar; small amounts of iron, etc. The chemical compositions (\%) by X-ray fluorescence analysis were shown in Table 1. The rock powder was sieved with a 100 mesh sieve for experiment.

Table 1. Chemical compositions (\%) of the tested rocks

\begin{tabular}{c|c|c|c|c|c|c|c|c|c|c|c}
\hline \multirow{2}{*}{$\begin{array}{c}\text { Rock } \\
\text { type }\end{array}$} & \multicolumn{10}{c}{ Chemical composition (\%) } \\
\cline { 2 - 12 } & $\mathbf{S i O}_{2}$ & $\mathbf{T i O}_{2}$ & $\mathbf{A l}_{3} \mathbf{O}_{2}$ & $\mathbf{F e}_{2} \mathbf{O}_{3}$ & $\mathbf{M n O}$ & $\mathbf{M g O}$ & $\mathbf{C a O}$ & $\mathbf{N a}_{2} \mathbf{O}$ & $\mathbf{K}_{2} \mathbf{O}$ & $\mathbf{P}_{2} \mathbf{O}_{5}$ & Other \\
\hline Granite & 74.29 & 0.20 & 13.54 & 1.88 & 0.37 & 0.28 & 0.78 & 3.49 & 4.78 & 0.04 & 0.35 \\
Gneiss & 78.12 & 0.22 & 11.67 & 1.18 & 0.47 & 0.27 & 0.66 & 5.72 & 0.98 & 0.01 & 0.70 \\
Sandstone & 97.45 & 0.06 & 0.99 & 0.53 & 0.09 & 0.04 & 0.08 & 0.17 & 0.16 & 0.01 & 0.51 \\
\hline
\end{tabular}

\section{$N$-containing medium}

Sucrose $10 \mathrm{~g}, \mathrm{KCl} 0.1 \mathrm{~g}$, $\left(\mathrm{NH}_{4}\right) \mathrm{SO}_{4} 1.0 \mathrm{~g}, \mathrm{CaCO}_{3} 1.0 \mathrm{~g}, \mathrm{Na}_{2} \mathrm{HPO}_{4} \cdot 12 \mathrm{H}_{2} \mathrm{O} 2.0 \mathrm{~g}$, $\mathrm{MgSO}_{4} \cdot 7 \mathrm{H}_{2} \mathrm{O} 1.0 \mathrm{~g}$, distilled water $1.0 \mathrm{~L}$.

The $B$. mucilaginosus were cultured on $\mathrm{N}$-containing medium for $3 \mathrm{~d}$ to activate the bacteria. The $\mathrm{pH}$ value was adjusted by $0.1 \mathrm{~mol} \bullet \mathrm{L}^{-1} \mathrm{HCl}$ and $\mathrm{NaOH}$ in the preparation of $\mathrm{N}$-containing medium.

\section{Experimental methods}

\section{The test of weathering rock by $B$. mucilaginosus}

The B. mucilaginosus was inoculated in $250 \mathrm{~mL}$ culture solution for $56 \mathrm{~h}$, centrifuged at $5000 \mathrm{rpm}$ for $10 \mathrm{~min}$, and then washed with sterile water for 3 times, and $600 \mathrm{~mL}$ of sterile water was added as the inoculation solution. $150 \mathrm{~mL}$ liquid medium was first added into a $500 \mathrm{~mL}$ triangular flask, and then $5 \mathrm{~g}$ granite powder or $5 \mathrm{~g}$ gneiss powder or $5 \mathrm{~g}$ sandstone powder was added. Sterile filter membrane was used for sealing. $121 \mathrm{C}$ high pressure sterilization for $20 \mathrm{~min}$, to add $5 \%$ B. mucilaginosus spore suspension $\left(10^{7} / \mathrm{mL}\right)$ at $28^{\circ} \mathrm{C}$ (plus or minus $0.5 \mathrm{C}$ ) for static culture after cooling, and the contents of organic acids, polysaccharides, $\mathrm{pH}$ value, $\mathrm{Si}, \mathrm{Fe}, \mathrm{Al}, \mathrm{Ca}, \mathrm{K}$ and $\mathrm{Mg}$ in the fermentation broth were determined at $2 \mathrm{~d}, 5 \mathrm{~d}, 10 \mathrm{~d}, 15 \mathrm{~d}, 22 \mathrm{~d}$ and $30 \mathrm{~d}$ respectively. Compare with no bacteria, repeat three times. The experimental period was $30 \mathrm{~d}$ (Wu, 2018).

\section{Observation of the surface morphology of weathering rock by B. mucilaginosus}

The powders of granite, gneiss, and sand rock were collected respectively after experiment processing, and dried at $50 \mathrm{C}$. Then the samples were fixed, sprayed gold. 
The surface characteristics of rocks were observed using a Scanning Electron Microscopy (SEM) (Neo Scope JCM - 5000) after $30 \mathrm{~d}$.

\section{Method of measurement}

\section{Determination of organic acids}

$1 \mathrm{~mL}$ of filtered fermented liquid after cultured $10 \mathrm{~d}$ was sucked up and put into the centrifuge tube with $10 \mathrm{~mL}$ from the test samples treated by the spore suspension liquid of B. mucilaginosus, $200 \mu \mathrm{L}$ of $50 \% \mathrm{H}_{2} \mathrm{SO}_{4}$ were add into it, which was centrifuged with $10000 \mathrm{r} / \mathrm{min}$ for $5 \mathrm{~min}, 500 \mu \mathrm{L}$ of supernatant were taken, and filtered with the $0.45 \mu \mathrm{m}$ filter membrane, the contents of 6 kinds of organic acids (oxalic acid, tartaric acid, citric acid, acetic acid, malic acid and succinic acid) were determined by means of High Performance Liquid Chromatography (HPLC, 1260 Infinity, Agilent Technologies, USA) method (Wu, 2018).

\section{Determination of amino acids}

$2 \mathrm{~mL}$ of filtered fermented liquid after cultured $10 \mathrm{~d}$ were sucked up and put into the centrifuge tube with $10 \mathrm{~mL}$ from the test samples treated by the spore suspension liquid of B. mucilaginosus, $2 \mathrm{~mL}$ of sulfosalicylic acid solution were accurately added into it, blended and vibrated overnight at $4 \mathrm{C}$; then $1 \mathrm{~mL}$ of EDTA-Na solution with $50 \mathrm{~g} / \mathrm{L}$ and $1 \mathrm{~mL}$ of $\mathrm{HCl}$ solution with $0.06 \mathrm{~mol} / \mathrm{L}$ were added into it, mixed, and centrifuged with $10,000 \mathrm{r} / \mathrm{min}$ for $5 \mathrm{~min}$, their supernatant liquids were sucked up, and freeze-dried; then $1 \mathrm{~mL}$ of sodium citrate buffer solution was added to make the concentration of amino acid be in the best detection range, and the contents of different amino acids in the fermentation liquid were determined by the amino acid tester (Germany, sykam S433D) (Wu, 2018).

\section{Determination of polysaccharides}

$2 \mathrm{~mL}$ of filtered fermented liquid after cultured $10 \mathrm{~d}$ were sucked up and put into the centrifuge tube with $10 \mathrm{~mL}$ from the test samples treated by the spore suspension liquid of B. mucilaginosus, which was centrifuged with $8000 \mathrm{r} / \mathrm{min}$ for $20 \mathrm{~min}$, their supernatant liquids were taken, $60 \mathrm{~mL}$ of anhydrous ethanol were added, and put into refrigerator at $4 \mathrm{C}$ for $1 \mathrm{~h}$; then centrifuged with $6000 \mathrm{r} / \mathrm{min}$ for $20 \mathrm{~min}$, washed and precipitated with $95 \%$ of ethanol, anhydrous ethanol and ether precipitation respectively, the polysaccharide crude products were obtained after centrifugation, the removing protein processing were conducted by the Sevag reagent (chloroform: isoamyl alcohol = $4: 1$ ), and then dialyzed using deionized water, frozen at $-80 \mathrm{C}$ after about $24 \mathrm{~h}$, freeze-dried, a pure polysaccharide was gained and weighted, thus contents of polysaccharide in the fermented liquid of B. mucilaginosus were determined and compared in different rocks (Wu, 2018).

\section{Determination of the elements in the fermentation fluid}

$5 \mathrm{~mL}$ fermented liquid of cultured $2 \mathrm{~d}, 5 \mathrm{~d}, 10 \mathrm{~d}, 15 \mathrm{~d}, 30 \mathrm{~d}$ were respectively taken to centrifuge with $5000 \mathrm{r} / \mathrm{min}$ for $10 \mathrm{~min}$ from the test samples treated by the spore suspension liquid of B. mucilaginosus, then their supernatants were fetched and put into the volumetric flask to be constant volume with $50 \mathrm{~mL}, 5 \mathrm{~mL}$ of measured liquids were taken, and added 1 drop of concentrated nitric acid into it, the contents of various 
element of the processed samples were determined by inductively coupled plasma emission spectrometer Inductively Coupled Plasma Optical Emission Spectr (ICP-OES) (the Vista MXP type, USA).

\section{Results}

\section{Changes of the metabolites formed by B. mucilaginosus in different rocks}

Change trend of $\mathrm{pH}$ value of fermented liquids for B. mucilaginosus in different rock conditions

Figure 1 presented the change trend of $\mathrm{pH}$ value of fermented liquids for $B$. mucilaginosus with cultured time. It can be found that, with the extension of cultured time, $\mathrm{pH}$ value of the fermented liquids decreased first and then increased; within the cultivation of 1-10 d time, $\mathrm{pH}$ value declined rapidly, when cultivated $10 \mathrm{~d}$, the $\mathrm{pH}$ value achieved minimum, subsequently, with the extension of cultured time, $\mathrm{pH}$ value had a rising trend gradually; Under different rock conditions, the variation trend of $\mathrm{pH}$ value was similar, the rangeability of $\mathrm{pH}$ value varied differently, with the highest $\mathrm{pH}$ value (4.59) in sandstone, secondly $\mathrm{pH}$ value (4.48) in gneiss, and lowest $\mathrm{pH}$ value (4.34) in granite, but three all were significantly lower than the control $\mathrm{pH}$ value (5.88, $\mathrm{p}<0.05)$. In the experimental system containing $B$. mucilaginosus, the $\mathrm{pH}$ value first decreased and then increased, which may be because of $B$. mucilaginosus producing metabolites such as organic acids, polysaccharides and amino acids, which were gradually ionized as $\mathrm{H}+$, resulting in a lower $\mathrm{pH}$ value of fermentation broth. The increase of $\mathrm{pH}$ value in the later stage of the experiment may be related to the autolysis of bacterial cells.

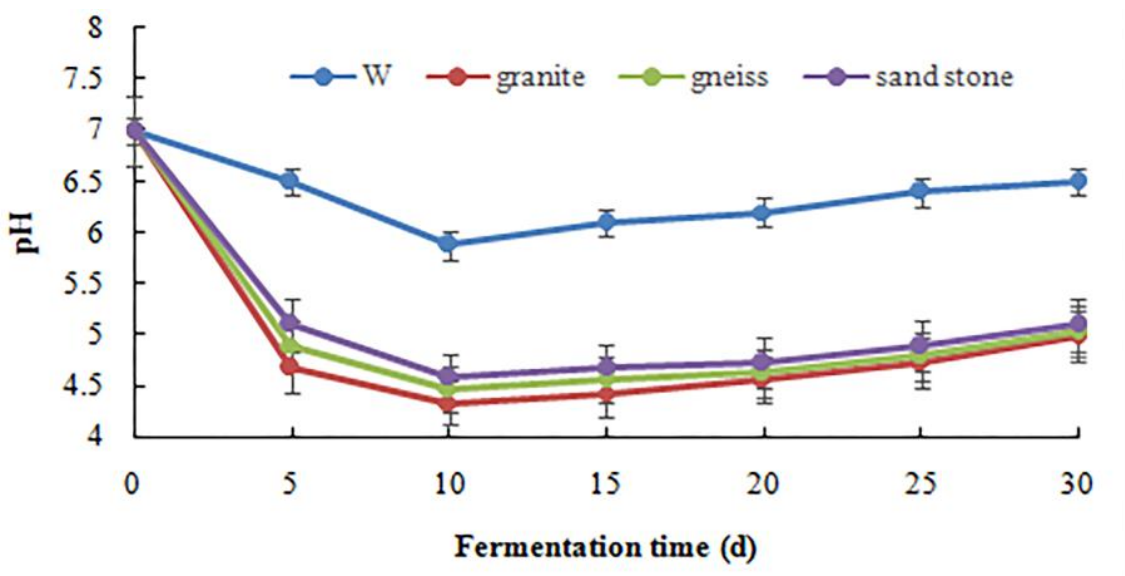

Figure 1. Change of contents of $p H$ values of the fermented liquids for B. mucilaginosus in different rocks

Changes of types and contents of organic acids in the fermented liquids of $B$. mucilaginosus in different rocks

Organic acid is one of metabolites of $B$. mucilaginosus, reflects the ability of mineral leaching and silicon dissolving of B. mucilaginosus to a certain extent. The contents of 6 organic acids (oxalic acid, citric acid, malic acid, tartaric acid, acetic acid and succinic acid) in the fermentation broth of B. mucilaginosus at the 10th d were measured (at this 
time, the $\mathrm{pH}$ value of the fermentation liquids was the smallest, as shown in Fig. 1). The contents of organic acids in the fermentation fluids in different rocks were found to be significantly different (Fig. 2). Among them, the contents of various organic acids in the fermentation fluids for granite were highest, followed by gneiss, and the lowest the sandstone, and three all were significantly higher than the control (without rock) ( $p<0.05$, Table 2). From the perspective of the types of organic acids, the three types of rocks all produced six organic acids, while the control produced only five organic acids, without citric acid; From the perspective of the contents of organic acid, among 6 kinds of organic acid, of tartaric acid were the most (1225.51), followed by glucose acid (1077.29), succinic acid (198.55), malic acid (116.61), and oxalic acid (76.11) and citric acid (55.78) the lower.

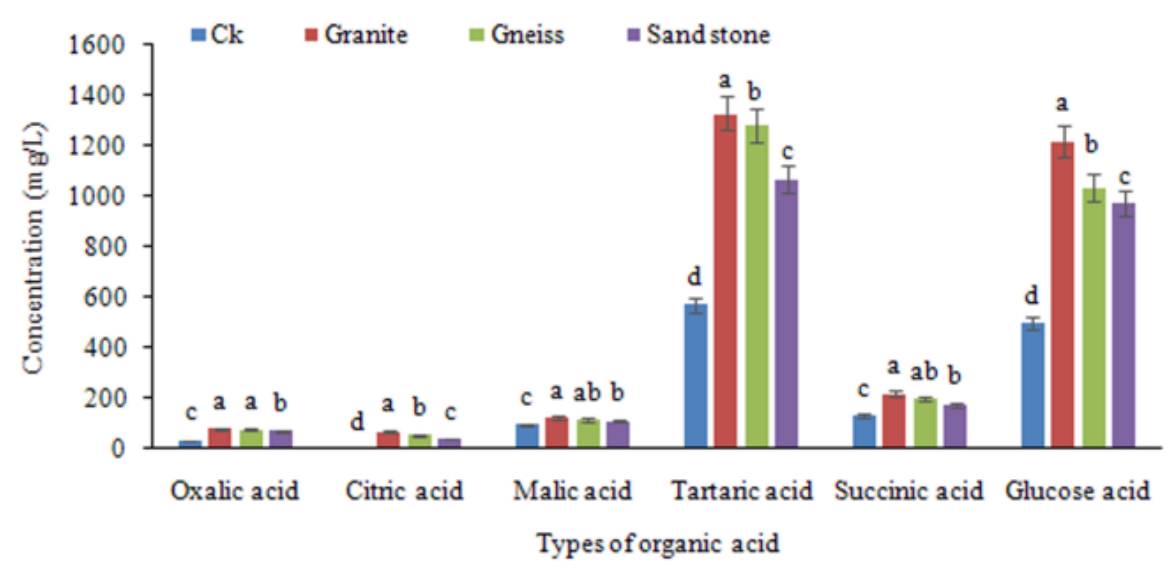

Figure 2. Types and contents of organic acids in the fermented liquids of B. mucilaginosus for different rocks

Changes of amino acid contents in the fermentation liquids of B. mucilaginosus for different rocks

Table 2 showed the types and contents of amino acids in the fermentation liquids at the cultured 10th d. It was obvious that the types and content of amino acids in the fermentation fluids between different rocks were different. 19 kinds of amino acids were detected out in fermented liquids for granite and gneiss, 18 kinds of amino acids for sandstone (methionine was not detected out), and just 8 kinds of amino acids for the control (without rock), which suggested that the types of amino acid produced in fermented liquids in added rock powder were more than in control (without rock powder). In other words, the rock powder to add in the fermented liquid stimulated $B$. mucilaginosus to produce more amino acids.

It can be seen from Table 2 that the contents of amino acids in fermented liquids of B. mucilaginosus in different rocks were significant different, and its size sequence was granite $>$ gneiss $>$ sandstone $>$ control, and the composition of amino acids was different obviously in different rock except control. Among them, the contents of alanine were the most, followed by cysteine, glutamic acid, glycine, leucine, isoleucine, methionine content in the least. This result further indicates that different rocks stimulate the fermentation broth of silicate bacteria to produce different metabolites, that is to say, microorganisms have certain selectivity to destroy the mineral rocks with different structures. 
Table 2. Types and contents of amino acids in the fermented liquids of B. mucilaginosus for different rocks

\begin{tabular}{c|c|c|c|c|c}
\hline \multirow{2}{*}{ Types of amino acids $(\boldsymbol{\mu g} / \mathbf{L})$} & \multicolumn{5}{|c}{ Culture environment } \\
\cline { 3 - 6 } & & Without rock $(\mathbf{C k})$ & Granite & Gneiss & Sandstone \\
\hline & Glycine & $0.619 \pm 0.040 \mathrm{c}$ & $1.633 \pm 0.045 \mathrm{a}$ & $1.450 \pm 0.025 \mathrm{a}$ & $1.006 \pm 0.002 \mathrm{~b}$ \\
& Alanine & - & $2.112 \pm 0.063 \mathrm{a}$ & $1.366 \pm 0.042 \mathrm{~b}$ & $1.016 \pm 0.02 \mathrm{c}$ \\
& Valine & - & $0.788 \pm 0.002 \mathrm{a}$ & $0.568 \pm 0.002 \mathrm{~b}$ & $0.478 \pm 0.002 \mathrm{c}$ \\
Nonpolar & Leucine & $0.412 \pm 0.004 \mathrm{~d}$ & $1.483 \pm 0.021 \mathrm{a}$ & $1.096 \pm 0.036 \mathrm{~b}$ & $0.636 \pm 0.004 \mathrm{c}$ \\
amino acid & Isoleucine & - & $1.432 \pm 0.033 \mathrm{a}$ & $0.738 \pm 0.005 \mathrm{~b}$ & $0.776 \pm 0.003 \mathrm{~b}$ \\
& Proline & - & $0.509 \pm 0.001 \mathrm{a}$ & $0.326 \pm 0.004 \mathrm{c}$ & $0.423 \pm 0.005 \mathrm{~b}$ \\
& Methionine & $0.086 \pm 0.001 \mathrm{c}$ & $0.185 \pm 0.009 \mathrm{~b}$ & $0.332 \pm 0.003 \mathrm{a}$ & - \\
& Tryptophan & - & $0.175 \pm 0.002 \mathrm{~b}$ & $0.123 \pm 0.002 \mathrm{c}$ & $0.223 \pm 0.001 \mathrm{a}$ \\
& Phenylalanine & - & $0.359 \pm 0.001 \mathrm{~b}$ & $0.450 \pm 0.003 \mathrm{a}$ & $0.432 \pm 0.003 \mathrm{ab}$ \\
\hline \multirow{4}{*}{ Polar amino } & Tyrosine & $0.239 \pm 0.033 \mathrm{c}$ & $0.462 \pm 0.003 \mathrm{a}$ & $0.455 \pm 0.005 \mathrm{a}$ & $0.316 \pm 0.003 \mathrm{~b}$ \\
acid & Threonine & $0.083 \pm 0.001 \mathrm{c}$ & $0.222 \pm 0.004 \mathrm{a}$ & $0.178 \pm 0.002 \mathrm{~b}$ & $0.218 \pm 0.001 \mathrm{a}$ \\
& Serine & - & $0.246 \pm 0.002 \mathrm{a}$ & $0.218 \pm 0.002 \mathrm{~b}$ & $0.076 \pm 0.001 \mathrm{c}$ \\
& Cysteine & - & $1.976 \pm 0.058 \mathrm{a}$ & $0.968 \pm 0.003 \mathrm{~b}$ & $0.561 \pm 0.004 \mathrm{c}$ \\
& Asparaginate & - & $0.122 \pm 0.003 \mathrm{a}$ & $0.114 \pm 0.001 \mathrm{~b}$ & $0.105 \pm 0.001 \mathrm{c}$ \\
\hline \multirow{2}{*}{ Alkaline } & Histidine & $0.126 \pm 0.037 \mathrm{c}$ & $0.654 \pm 0.042 \mathrm{a}$ & $0.582 \pm 0.005 \mathrm{a}$ & $0.402 \pm 0.003 \mathrm{~b}$ \\
amino acid & Arginine & - & $0.964 \pm 0.065 \mathrm{a}$ & $0.866 \pm 0.004 \mathrm{~b}$ & $0.749 \pm 0.005 \mathrm{c}$ \\
& Lysine & - & $1.043 \pm 0.068 \mathrm{a}$ & $0.916 \pm 0.003 \mathrm{~b}$ & $0.815 \pm 0.002 \mathrm{c}$ \\
\hline Acidic amino & Aspartic acid & $1.134 \pm 0.081 \mathrm{c}$ & $1.546 \pm 0.032 \mathrm{a}$ & $1.324 \pm 0.035 \mathrm{~b}$ & $1.101 \pm 0.021 \mathrm{c}$ \\
acid & Glutamic acid & $0.215 \pm 0.051 \mathrm{~b}$ & $1.685 \pm 0.422 \mathrm{a}$ & $1.555 \pm 0.046 \mathrm{a}$ & $1.360 \pm 0.036 \mathrm{a}$ \\
\hline
\end{tabular}

"_" indicates that data is not detected

Changes of polysaccharide contents in the fermentation fluids of B. mucilaginosus for different rocks

The contents of polysaccharides in the fermentation liquid at cultured $10^{\text {th }} \mathrm{d}$ were shown in Figure 3. It can be seen that there were obvious differences in the contents of polysaccharides in the fermentation liquid of $B$. mucilaginosus for different rocks. The contents of polysaccharide in the fermentation liquids of $B$. mucilaginosus in the addition of rock powders were significantly higher than that of the control (without rock powder), indicating that the rock powder added in the medium stimulates the $B$. mucilaginosus to produce more polysaccharides. At the same time, we can see from Figure 3 that the B. mucilaginosus have different effect of yielding sugars in different rocks. Among them, the contents of polysaccharide in the fermentation liquids in granite were the highest, which had no significant difference with gneiss, but was significantly higher than that of sandstone and control.

\section{The weathering effect of the B. mucilaginosus on different rocks}

The dissolution effect of the B. mucilaginosus on the elements in different rocks

Figure 4 showed the dissolution effect of $B$. mucilaginosus on different oxides in granite, gneiss and sandstone. The data in the figure were obtained from the content of oxide in the fermentation broth minus that of the control (without B. mucilaginosus). It was observed from the figure that with the increase of culture time, concentration of 
each oxide was significantly increased, a good growth effect of the B. mucilaginosus in the culture liquids added rock was showed, which indicated that the three kinds of rocks could promote the growth and reproduction of $B$. mucilaginosus, and further showed that $B$. mucilaginosus had a certain weathering effect on the three kinds of rocks. According to the amount of oxides leached from the three kinds of rock fermentation liquid, more oxides such as $\mathrm{SiO}_{2}, \mathrm{Na}_{2} \mathrm{O}, \mathrm{P}_{2} \mathrm{O}_{5}, \mathrm{Fe}_{2} \mathrm{O}_{3}, \mathrm{Al}_{2} \mathrm{O}_{3}, \mathrm{CaO}, \mathrm{K} 2 \mathrm{O}, \mathrm{MgO}, \mathrm{TiO}_{2}$ were dissolved from fermentation liquid in the granite. Compared with sandstone, they increased by $17.28,5.71,2.27,22.96,5.99,17.15$. 16.80, 1.93 and $0.65 \mathrm{mg} / \mathrm{L}$ respectively; compared with gneiss, they increased by 14.24, 3.51, 1.48, 6.80, 1.55, $5.39,1.93,0.70$ and $2.43 \mathrm{mg} / \mathrm{L}$, respectively. $\mathrm{MnO}$ was dissolved in the highest quantities in the fermentation broth of gneiss, more than that of granite and sandstone, which was increased by $0.41 \mathrm{mg} / \mathrm{L}$ and $.50 \mathrm{mg} / \mathrm{L}$, respectively.

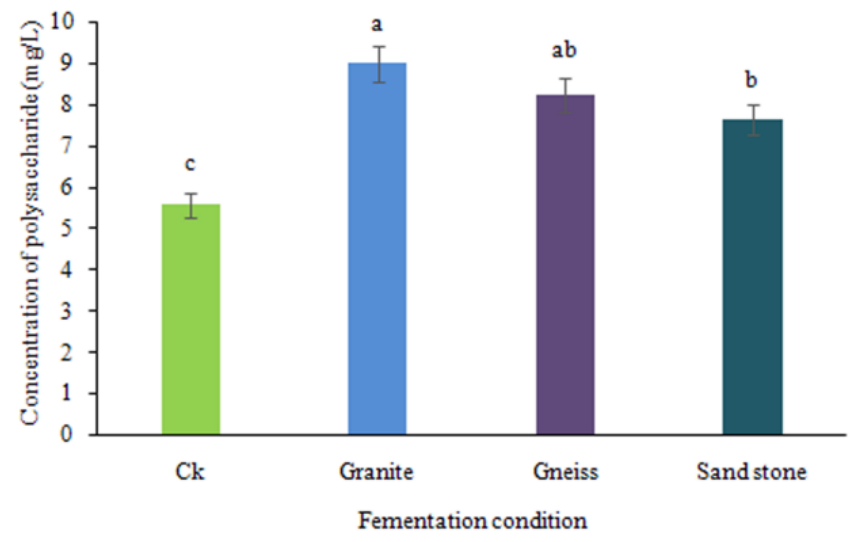

Figure 3. Change of contents $(\mathrm{mg} / \mathrm{L})$ of polysaccharide in the fermentation liquids of $B$. Mucilaginosus for different rocks

It can also be seen from Figure 4 and Table 1 that the weathering effect of $B$. mucilaginosus on rocks is closely related to the structural components of rocks. In addition to $\mathrm{SiO}_{2}, \mathrm{TiO}_{2}$ and $\mathrm{Na}_{2} \mathrm{O}$, in general, the higher the content of a certain chemical component in rocks, the more the chemical component dissolved by B. mucilaginosus. For example, granite and gneiss have similar structural components, mainly composed of quartz and feldspar, so the weathering effect of the two kinds of rock fermentation liquid is also similar. The main reason why the element dissolution of gneiss is lower than that of granite is that the content of this element in the rock component is slightly lower than that of granite. The main component of sandstone is quartz, the content of $\mathrm{SiO}_{2}$ is greater than $95 \%$, and the content of other element oxides is less, so the dissolution concentration of oxides of other nine elements in the three types of rocks is low. It should be pointed out that the content of $\mathrm{SiO}_{2}$ in sandstone is extremely high, ranking the first among the three types of rocks, but its dissolution concentration is the lowest, and the reason remains to be further discussed.

\section{Morphological changes and analysis of rock samples before and after dissolution}

The observation results of fore-and-aft of granite, gneiss and sandstone weathered by B. mucilaginosus with the scanning electron microscope were shown in Figure 5. 
a
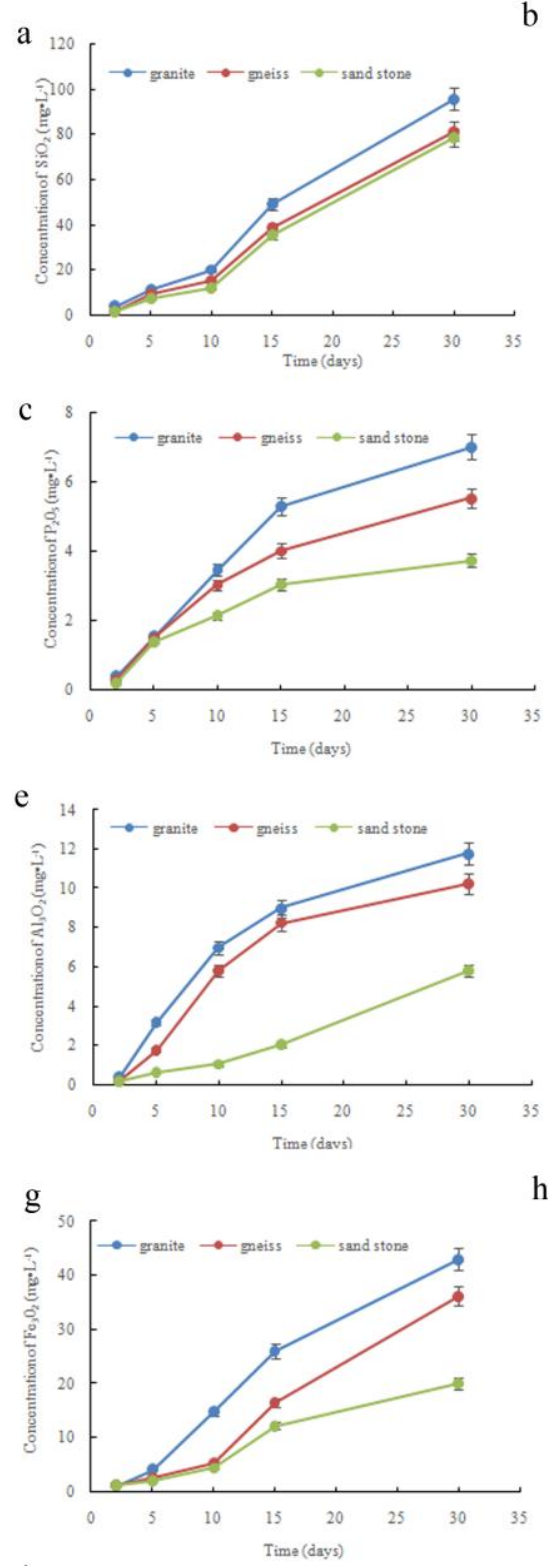

i

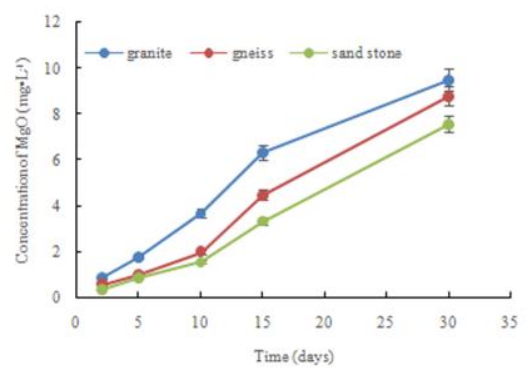

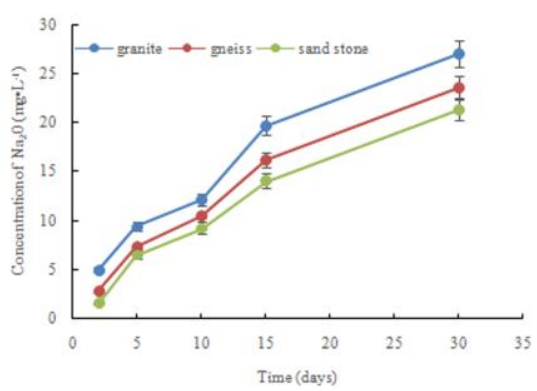

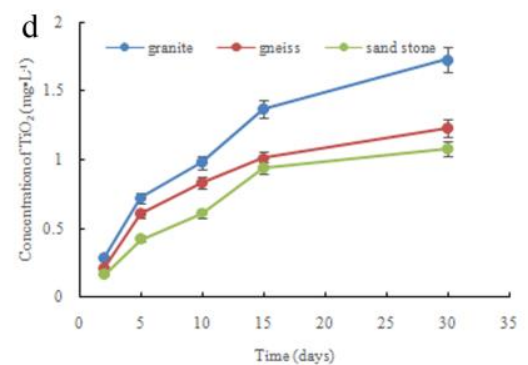

f
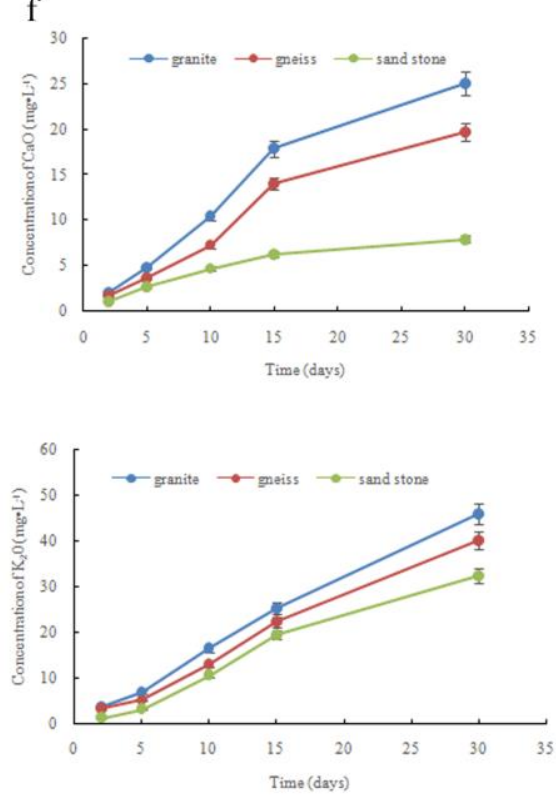

$\mathrm{j}$

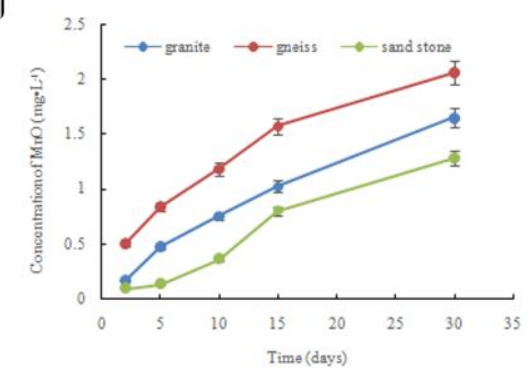

Figure 4. The concentration of various oxides in the fermentation broth of B. mucilaginosus for different rocks

Figure $5 a, b, c$ were surface appearance of granite, gneiss, and sandstone rock that were not contacted with $B$. mucilaginosus respectively, it can be seen that the surface of rock particles was smooth, angular, obvious uneven shape, complete crystal structure; 
Figure $5 f$ was the surface topography of sandstone corroded by B. mucilaginosus at cultured $30 \mathrm{~d}$, its surface structure was basically destroyed, blurred edges and corners, with some small caves and fractures; Figure $5 e$ was the surface appearance of gneiss rock corroded by B. mucilaginosus at cultured $30 \mathrm{~d}$, and its angular surface became smooth, the large corner angle and the bulge were broken up into smaller angular and smaller particles, with more corrosion holes and cracks. Figure $5 d$ was the surface appearance of granite corroded by B. mucilaginosus at cultured $30 \mathrm{~d}$. It can be seen from the Figure $5 d$ that the surface structure of granite was completely destroyed, its raised edges and corners was completely blurred, and its surface became rough and uneven. These fully demonstrated that the B. mucilaginosus had obvious weathering effect on the surface of three kinds of rocks, and the weathering effect of granite was most distinct.

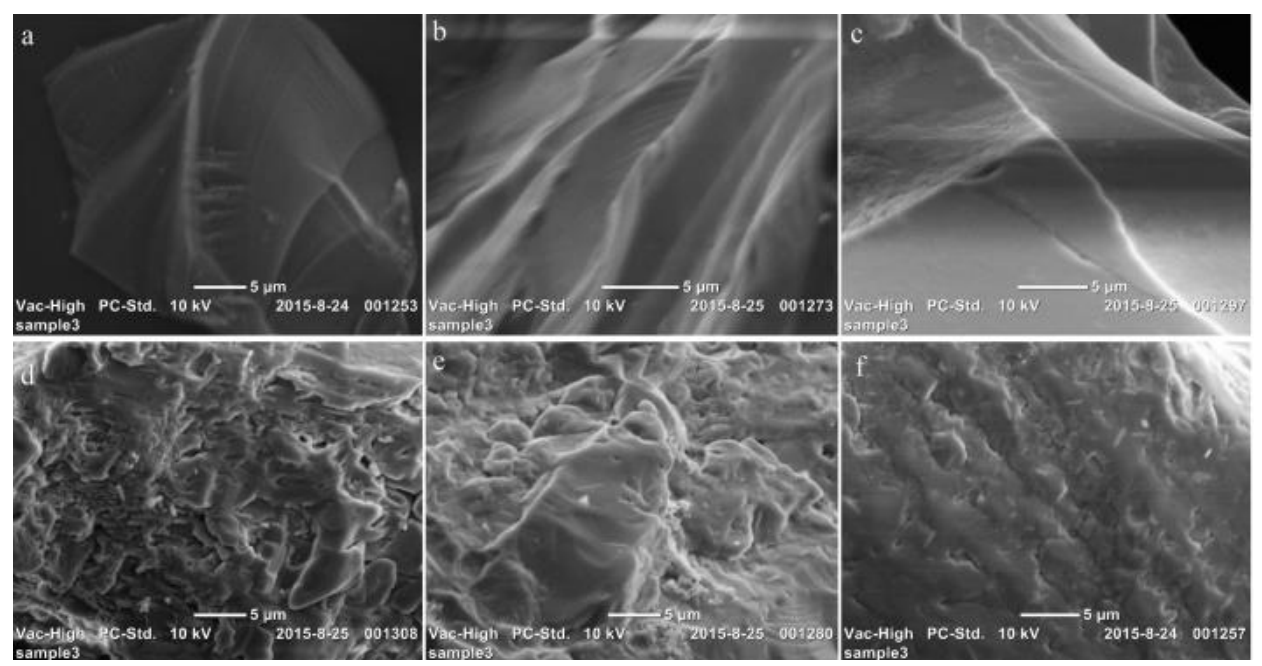

Figure 5. Electron micrograph of B. mucilaginosus before and after weathering rocks. $a$ control for weathered granite; $b$ - control for weathered gneiss; $c$ - control for weathered sandstone; $d$ - photograph for weathered granite; photograph for weathered gneiss; $f$ photograph for weathered sandstone

\section{Discussion}

Most researchers believe that acid hydrolysis is an important way for microorganisms to promote rock and mineral weathering. In this experiment, organic acids such as oxalic acid, citric acid and succinic acid produced in the fermentation broth had good dissolution effects on granite, gneiss and sandstone. It has been proved by studies that under the condition of mineral properties and the same $\mathrm{pH}$ value, organic acid solution is more likely to dissolve silicate minerals than inorganic acid solution (Bennett, 1996), because organic acid has both acid dissolution and complexation in the dissolution of silicate minerals, and complexation plays an important role in the dissolution of silicate minerals by organic acid.

Previous studies have shown that $B$. mucilaginosus can promote the weathering of potassium feldspar, illite, quartz, plagioclase and kaolin (Sun, 2006; Ren, 2015). The results showed that $B$. mucilaginosus also had obvious weathering effect on granite, gneiss and sandstone. This was basically consistent with the results of previous studies. However, compared with Sun Side's experiment of promoting silica, plagioclase and 
kaolinite to dissolve silicon and aluminum by using the JXF strain of B. mucilaginosus (Sun, 2008), two kinds of organic acids (acetic acid and succinic acid) and three kinds of amino acids (tryptophan, threonine and histidine) were detected in the fermentation broth. These metabolites undoubtedly play an important role in the weathering of rocks by $B$. mucilaginosus.

The fermentation broth of B. mucilaginosus could dissolve the elements contained in granite, gneiss and sandstone, such as phosphorus, potassium, silicon, sodium, magnesium, iron and calcium. With the extension of fermentation time, the content of released elements increased. Among them, the weathering effect of the granite was best, followed by gneiss, that of the sandstone was weak. The results of this study fully confirmed that $B$. mucilaginosus could promote weathering of granite, gneiss and sandstone, and elucidate its dissolution effect on phosphorus, potassium, silicon, sodium, magnesium, iron and calcium and other elements, but its dissolution effect had certain selectivity to rock types. Phosphorus and potassium are essential macroelements for plants. Sodium, magnesium, iron and calcium are essential microelements for plants. Although silicon is not a necessary element for plants, it is also a beneficial element. Once applied to the restoration of abandoned rock mining areas, B. mucilaginosus will promote the dissolution of available nitrogen, phosphorus, potassium, silicon, sodium, magnesium, iron and calcium in the soil, increase the contents in the soil, improve the status of soil nutrient poverty, so as to enable plants to obtain sufficient nutrients to promote the growth of plants (Zhang et al., 2016).

Granite, gneiss and sandstone are widely distributed in China, which are the three rock types in Jiangsu province. Their bare rock needs repairing. The experiment results showed that the B. mucilaginosus could effectively weather the three rocks. Its application in the restoration of bare rock will undoubtedly help to solve the problems of soil erosion and vegetation growth in Jiangsu province and even the whole country, and it is of great significance and value to accelerate the rock slope greenization project and realize the sustainable development of ecological environment. As for how $B$. mucilaginosus mixes with other microbial species, plant seeds, soil, etc. remains to be further studied.

\section{Conclusion}

In the fermentation broth of $B$. mucilaginosus added with granite, gneiss and sandstone respectively, their $\mathrm{pH}$ values showed a tendency of first decreasing and then increasing with the extension of culture time.

B. mucilaginosus can promote the dissolution effect of granite, gneisses and sandstone by secreting organic acids, amino acids, polysaccharides and other metabolites. Different rocks stimulate B. mucilaginosus to produce different metabolites. The contents of various organic acids, amino acids and polysaccharides in the fermentation liquid of granite were the highest, followed by gneiss, and sandstone was the lowest. More 9 kinds of oxides such as $\mathrm{SiO}_{2}, \mathrm{Na}_{2} \mathrm{O}, \mathrm{P}_{2} \mathrm{O}_{5}, \mathrm{Fe}_{2} \mathrm{O}_{3}, \mathrm{Al}_{2} \mathrm{O}_{3}, \mathrm{CaO}$, $\mathrm{K}_{2} \mathrm{O}, \mathrm{MgO}$ and $\mathrm{TiO}_{2}$ were dissolved in fermentation broth added with granite.

B. mucilaginosus can significantly promote the weathering of granite, gneiss and sandstone, especially granite. SEM observation showed that after 30 days of dissolution by $B$. mucilaginosus, the edges and corners of sandstone rock became blurred, the edges and corners of gneiss rock smooth, and the convex edges and corners of granite surface rough, and obvious corrosion pits appeared in all three kinds of rocks. 
This paper provided a good seed resources for solving the problem of rapid soil formation of exposed rocks in abandoned mining areas and a new idea and solution for ecological restoration of degraded habitats. However, the effective combination of $B$. mucilaginosus with other microbial species, plant seeds and soil still needs to be further studied.

Acknowledgements. This research was supported by the positioning research project of Forest Ecosystem of Changjiang River Delta in Jiangsu Province, the Engineering Project 'Three New' for Forestry in Jiangsu Province (lysx [2013] 10), a project funded by the Priority Academic Program Development of Jiangsu Higher Education Institutions, the open project of the Key Laboratory of Soil and Water Conservation and Ecological Restoration in Jiangsu Province, and a Fund Project of the Anyang Institute of Technology (YJJ2015011).

\section{REFERENCES}

[1] Barker, W. W., Banfield, J. F. (1998): Zones of chemical and physical interaction at interfaces between microbial communities and minerals: a model. - Geomicrobiology Journal 15(3): 223-244.

[2] Bennett, P. C., Hiebert, F. K., Wan, J. C. (1996): Microbial colonization and weathering of silicates in a petroleum-contaminated groundwater. - Chemical Geology 132(1-4): 4553.

[3] Du, L. T., Huang, Z. Z. (1984): Valence dipolarization in silicate rocks. - Geochimica 13(3): 273-281 (in Chinese).

[4] Ehrlich, H. L. (1998): Geomicrobiology: its significance for geology. - Earth-Science Reviews 45(1-2): 45-60.

[5] Fang, Y., Ma, R. T., An, S. S. et al. (2016): Heidaigou opencast coal mine: soil enzyme activities and soil physical and chemical properties under different vegetation restoration. - Environmental Science 37(3): 1121-1127 (in Chinese).

[6] Ge, H. L., Ji, X. E. (2017): Screening, Identification and promoting effects of potassiumsolubilizing bacteria in rhizosphere of cucumber. - Northern Horticulture 41(13): 21-25 (in Chinese).

[7] Hall, K., Arocena, J. M., Boelhouwers, J. et al. (2005): The influence of aspect on the biological weathering of granites: observations from the Kunlun Mountains, China. Geomorphology 67(1-2): 171-188.

[8] Li, J., Yuan, H. S., Wang, W. et al. (2016): Isolation of silicate bacteria from paddy field and determination of activity of the strain. - Ecological Science 35(1): 103-108 (in Chinese).

[9] Li, S., Li, F. C., Cheng, L. J. (2006): Recent development in bio-weathering research. Mineral Resources and Geology 20(6): 577-582 (in Chinese).

[10] Li, Y., Li, F. C., Yang, G. et al. (2017): Comparing elements dissolution from biotite bioweathering by bacteria and fungi. - Chinese Journal of Soil Science 48(1): 86-93 (in Chinese).

[11] Man, L. Y., Xiao, G. G., Zhang, X. Z. (2015): Bioleaching of bauxite by silicate bacteria and change of bacterial community structure during leaching process. - Journal of Central South University (Science and Technology) 46(2): 394-403 (in Chinese).

[12] Ren, L. L., Li, Y. X., Chen, Y. (2015): Research progress on silicate bacteria potassium releasing. - Experiment Science and Technology 13(2): 209-211 (in Chinese).

[13] Song, M., Peng, Y. X., Pedruzzi, I. et al. (2015): Bioweathering and K release of Kbearing minerals by Penicillium oxalicum. - Microbiology China 42(7): 1410-1417 (in Chinese). 
[14] Štyriaková, I., Štyriak, I., Oberhansli, H. (2012): Rock weathering by indigenous heterotrophic bacteria of Bacillus spp. at different temperature: a laboratory experiment. Mineralogy and Petrology 105(3-4): 135-144.

[15] Sun, D. S., Zhang, X. Z., Zhang, Q. (2006): Leaching effects of metabolites of silicate bacterium on silicate minerals. - Mining and Metallurgical Engineering 26(3): 39-42 (in Chinese).

[16] Sun, D. S., Wan, Q., Zhao, X. P. (2008): Metabolites of Bacillus mucilaginous JXF and their desiliconization effect. - Mining and Metallurgical Engineering. 28(3): 52-56 (in Chinese).

[17] Sun, H. Z., Song, P., Du, J. et al. (2018): Identification of silicate bacterium and its breeding by UV mutation. - Genomics and Applied Biology 37(3): 1225-1230 (in Chinese).

[18] Vandevivere, P., Welch, S. A., Ullman, W. J. et al. (1994): Enhanced dissolution of silicate minerals by bacteria at near-neutral pH. - Microbial Ecology 27(3): 241-251.

[19] Wang, R. R., Wang, Q., He, L. Y. et al. (2015): Isolation and the interaction between a mineral-weathering Rhizobium tropici Q34 and silicate minerals. - World Journal of Microbiology and Biotechnology 31(5): 747-753.

[20] Welch, S. A., Ullman, W. J. (1993): The effect of organic acids on plagioclase dissolution rates and stoichiometry. - Geochimica et Cosmochimica Acta 57(12): 2725-2736.

[21] Wu, Q. F., Hu, H. B. (2019): The influence of environmental factors on Aspergillus niger granite weathering. - Applied Ecology and Environmental Research 17(1): 395-408.

[22] Wu, Q. F., Fu, L., Lu, Z. F. (2016): Purification and molecular identification experiments of microbe in soil. - Journal of Anyang Institute of Technology 15(4): 27-29 (in Chinese).

[23] Wu, Q. F., Hu, H. B., Zhang, X. (2018): Effect of Aspergillus niger and its metabolites on weathering of granite. - Journal of Nanjing Forestry University (Natural Sciences Edition) 42(1): 81-88 (in Chinese).

[24] Wu, Y. W., Zhang, J. C., Guo, X. P. et al. (2017a): Identification of efficient strain applied to mining rehabilitation and its rock corrosion mechanism: based on boosted regression tree analysis. - Environmental Science 38(1): 283-293 (in Chinese).

[25] Wu, Y. W., Zhang, J. C., Wang, L. J. et al. (2017b): A rock-weathering bacterium isolated from rock surface and its role in ecological restoration on exposed carbonate rocks. - Ecological Engineering 101(1): 162-169.

[26] Xiao, G. G., Sun, D. S., Cao, F. (2013): Weathering of silicate minerals by metabolites produced by silicate bacteria in culture experiments. - Mineral Petrol. 33(3): 8-15 (in Chinese).

[27] Yang, J. L., Zhang, G. L., Huang, L. M. (2013): Rock weathering and soil formation rates of a forested watershed in the typical subtropical granite area. - Acta Pedolocica Sinica 50(2): 253-259 (in Chinese).

[28] Zeng, Q. (2016): Research progress on the mechanism of silicate bacteria on mineral weathering. - Science and Wealth 8(5): 931 (in Chinese).

[29] Zhang, H. F., He, G., Wu, L. Y. et al. (2018): Screening, identification and cultivated condition optimization of high efficiency potassium solubilization and desilication fungus strain. - Soils 50(5): 85-92 (in Chinese).

[30] Zhang, Y. X., Lei, P., Xu, Z. Q. et al. (2016): Screening of a high-efficiency phosphate solubilizing bacterium Bacillus subtilis JT-1 and its effects on soil micropecology and wheat growth. - Jiangsu Agricultural Science 32(5): 1037-1080 (in Chinese).

[31] Zhou, D. Z., Chen, Y., Cao, F. et al. (2015): Effects of chemical mutation on bacterial extracting potassium from potassium-rich sandshale. - The Chinese Journal of Nonferrous Metals 25(3): 824-833 (in Chinese). 